\title{
WCPT AFRICA TOGETHER TOWARDS 2000
}

I $t$ was a landmark in the history of South African Physiotherapy to have hosted the Fifth General Meeting of WCPT Africa, the first meeting to take place in our country. The meeting and Congress combined high academic standards with to quote Professor Dele Amonsun "the richness of African culture." It was a unique experience for South African Physiotherapists to share ideas with their African colleagues. We know that different countries do things differently and there is much to learn from one another and what a warm atmosphere to do this in! Dr Abe Nkomo, Chairperson of the Portfolio Committee on Health delivered the opening address. He reminded us in no uncertain terms of the challenges facing this country and more particularly in this context, physiotherapists in South Africa. To quote "The challenge is for physiotherapists to prove your critics who are labeling you technicians wrong and to broaden your scope of practice." Oh dear - are we still being labeled "technicians?" He urged us to redefine our role and be creative in our thinking. Primary health care, community based rehabilitation, empowering caregivers to carry out rehabilitation

\section{SUBSCRIPTION ORDER FORM}

(Non-SASP members)

PUBLICATIONS

SA Journal of Physiotherapy 4 issues -

Feb, May, Aug, Nov,

Physioforum 8 issues -

Jan, Mar, Apr, June, July, Sep, Oct, Dec,

SA Journal of Physiotherapy and

PhysioForum (12 issues per year)

Discount for early payment

(Before 1 Jan 1998)

LOCAL

OVERSEAS

R96.00

R240.00

R96.00

R240.00

R192.00

R480.00

$10 \%$

$10 \%$

Prices exclude $14 \%$ VAT and include postage costs. SASP members receive the South African Journal of Physiotherapy and Physioforum as part of their membership package. NB Should you wish to receive any publication airmail, please fax us for a quote.

Name

Postal address

Postal code

Country

Tel $(\mathrm{H})$

SASP membership number

Signature

Date

Please invoice me

Cheque enclosed.

Please send your payment to: Physiotherapy Publications,

South African Society of Physiotherapy, PO Box 92125,

Norwood, 2117, South Africa. Fax + 27114851613 and the whole question of student selection and education are not new concepts to us and we must be creative to bring about this change. Two of our keynote speakers, Professor Joan Cole from Australia and Professor Mariano Rocabado from Chile, brought input from the international community reminding us that the problems facing us are not that far off from those in other parts of the world. Mr Shnaib Chalklen, director of the office of the Status of Disabled Persons reinforced the need for physiotherapists to ensure that their work is effective and to become politically involved at government level, so that our services will be appropriately and judiciously used. The importance of these concepts should be emphasised at student level so that it does not seem so unrelated to our profession. This gathering of some 400 delegates from 19 different nations, many of whom are in different stages of facing challenges brought a togetherness of purpose to solve our mutual problems. It was also an opportunity for me to invite publications from African Countries as a means of sharing experiences with one another. It is hoped that we will be able to produce an all African Journal in February for distribution at The World Confederation of Physiotherapy in 1999 so that we can inform the world of the work that is being done in Africa. There are interesting, original and unique developments emanating from this continent - it would be our privilege to disseminate this information.

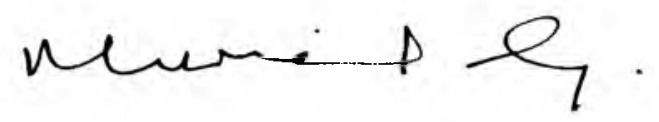

Notice is hereby given of a National

Assembly Meeting to be held on 5 and 6

September 1998 at Medical Distributors, 733

- 16th Road, Randjespark, Midrand,

Gauteng.There will be an Open Forum for

any member of the SASP who would like to

attend for matters of discussion - from 8-10

am on Saturday 5 September.

ADDRESS: South African Society of Physiotherapy, PO BOX 92125 Norwood 2117

Fax No: 788-5628 E-Mail Address: muriel@icon.co.za 